\title{
Review
}

\section{Influence of Gut Microbiota on Mental Health via Neurotransmitters: A Review}

\author{
Ting Liu ${ }^{1,2,3}$, K. Anton Feenstra ${ }^{2,3}$, Jaap Heringa ${ }^{2,3}$, Zhisheng Huang ${ }^{1, *}$ \\ ${ }^{1}$ Knowledge Representation and Reasoning (KRङR) Group, Vrije Universiteit Amsterdam, Amsterdam, De Boelelaan 1085, 1081 HV, The Netherlands \\ ${ }^{2}$ Center for Integrative Bioinformatics VU (IBIVU), Vrije Universiteit Amsterdam, Amsterdam, De Boelelaan 1085, $1081 \mathrm{HV}$, The Netherlands \\ ${ }^{3}$ Amsterdam Institute for Molecules Medicines and Systems (AIMMS), Vrije Universiteit Amsterdam, Amsterdam, De Boelelaan 1085, 1081 HV, The Netherlands
}

\section{ARTICLE INFO}

\section{Article History}

Received 29 Nov 2019

Accepted 30 Mar 2020

\section{Keywords}

Gut microbiota

Neurotransmitter

Mental disorders

Microbiota-gut-brain axis

\begin{abstract}
Mental disorders related to the imbalance of neurotransmitters, which are substantially affected by gut microbiota. Gut microbiota impacts on mental health by regulating the level of neurotransmitters in the host. To understand the influence of gut microbiota on mental health via neurotransmitters, we conducted a literature survey on the association between gut microbiota and neurotransmitters. We identified trustworthy evidences by critically appraising the related articles in terms of its evidence level. This paper provides a fairly comprehensive list of gut microbiota strains that can regulate neurotransmitters. Gut microbiota, neurotransmitters and mental disorders influence each other in a bidirectional way which form a triangle relationship. Understanding the triangle relationship benefits for the treatment of mental disorders. People who have experienced mental disorders may cure in the future by altering gut microbiota.
\end{abstract}

(C) 2020 The Authors. Published by Atlantis Press SARL. This is an open access article under the CC BY-NC license (http://creativecommons.org/licenses/by-nc/4.0/).

\section{INTRODUCTION}

Gut microbiota, the complex and dynamic population of microorganisms that live in the human gastrointestinal tract, has a significant influence on the mental health of the host. It has been demonstrated that gut microbiota is a contributor to several mental disorders, such as depression [1,2] and anxiety disorders [3]. Germ-free mice with gut microbiota from depressed patients show depression-like behaviors compare to the healthy control individuals $[4,5]$. That means depression is associated with an altered composition of gut microbiota. Proper regulation of probiotics can reduce the anxiety- and depression-related behaviors in mice [6,7], and ameliorate neuropsychiatric disorders [7]. Gut microbiota composition and diversity change associated with sleeping disorder [8] and eating disorders [9] in humans. These studies implicate that the dysbiosis of gut microbiota plays a causal role in the development of mental disorders. This causal relationship may involve the neurotransmitter imbalance caused by gut microbiota, as depicted in Figure 1.

Gut microbiota alters the level of neurotransmitters by producing neurotransmitters directly or regulating the related metabolism pathways [10]. The enteric nervous system, regarded as the human second brain, produces and utilizes more than 30 classes of neurotransmitters which are also identified in the central nervous system. It's well known that serotonin is a brain neurotransmitter, but more

*Corresponding author. Email: z.huang@vu.nl

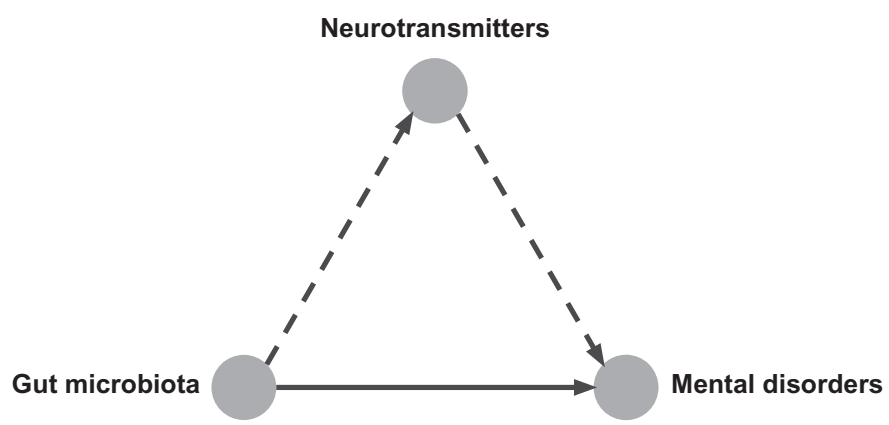

Figure 1 Gut microbiota affects mental health by regulating the level of neurotransmitters.

than $90 \%$ of the body's serotonin is synthesized in the digestive tract $[11,12]$. In addition to serotonin, the gut produces and stores about $50 \%$ of the body's dopamine $[13,14]$. Gut microbiota regulates the level of serotonin $[15,16]$ and dopamine $[7,17]$ in the host. More and more evidences prove that gut microbiota also produces or consumes other neurotransmitters, such as norepinephrine [18], gamma-aminobutyric acid (GABA) [6], histamine [19] and acetylcholine [20].

Abnormal neurotransmitter activities lead to mental disorders. Neurotransmitters play a crucial role in maintaining homeostasis for the human body. The result of interrupted neurotransmitters can lead to several mental disorders [21]. Depression is one of the mental disorders with significant potential for morbidity and 
mortality. Preclinical and clinical evidences show that depression accompanied by the disturbance in serotonin, dopamine and norepinephrine transmission in the central nervous system [22,23]. Serotonin network is the main target for most common classes of antidepressants [24]. Serotonin also has a well-confirmed role in the regulation of eating behaviors [25] and bipolar disorders [26]. In addition, serotonergic, noradrenergic and GABAergic systems mediate the sleep cycle [27] and some types of anxiety disorders $[28,29]$. The imbalance of neurotransmitters is one reason that responsible for the distress or impairment of personal mental health.

We hypothesize that gut microbiota influences on mental health by regulating the level of neurotransmitters (Figure 1). In this paper, we aim at understanding the association between gut microbiota and neurotransmitters. The contributions of this paper are (i) conducts a literature survey on the neurotransmitter modulation by gut microbiota; (ii) annotates research conclusions in that selected literature with evidence levels; (iii) provides a fairly comprehensive list of neurotransmitter producing gut microbiota; (iv) proposes a triangle relationship between gut microbiota, neurotransmitters and mental disorders; (v) discusses the possibility of treating mental disorders with gut microbiota interventions.

\section{MICROBIOTA-GUT-BRAIN AXIS}

Gut microbiota influences brain-related diseases by interacting with the enteric nervous system and the central nervous system via communication along the gut-brain axis [30-32]. This influence is generally achieved by multiple routes including the vagus nerve, the hypothalamic-pituitary-adrenal (HPA) axis, the immune system, cytokines production by the immune system, secretion of shortchain fatty acids (SCFAs), alteration of neurotransmitters level by producing neurotransmitters directly or regulating the tryptophan metabolism pathway [32-34]. We illustrate the microbiota-gutbrain axis as shown in Figure 2.

\subsection{Linking between Gut Microbiota and Mental Disorders}

The potential association between gut microbiota and mental disorders has been established in animal models. The patients with an anxiety disorder and depression have more gastrointestinal symptoms than the healthy controls $[35,36]$, which are related to the disorders of gut microbiota $[1,2,37]$. Compare to the healthy control, composition of gut microbiota in depression patients notable changes in the relative abundance of Firmicutes, Actinobacteria and Bacteroidetes [5]. Chronic administration probiotics, such as L. plantarum, reduce the anxiety- and depression-related behaviors [6] and induce changes in other emotional behaviors [7]. Hyperactive locomotor behaviors of germ-free fruit flies are rescued by single colonization of L. brevis [38]. The gut microbiota also has a crucial impact on host weight regulation, energy harvest from the diet or the host-derived compounds $[39,40]$. Such evidences indicate that gut microbiota has an influence on the mental health of the host.

\subsection{Regulation of Neurotransmitters by Gut Microbiota}

Gut microbiota has been reported to generate major neurotransmitters. In vitro studies reveal that $H$. alvei, K. pneumoniae and M. morganii strains produce serotonin, dopamine and histamine in histidine decarboxylase broth [17]. E. coli synthesizes serotonin, dopamine and norepinephrine in its growth medium during the late growth phase [41,42]. The association of germ-free mice with Clostridium species result in the drastic elevation of free norepinephrine and dopamine [18]. Some species of Lactobacillus increase the level of serotonin [7,43], dopamine [7], GABA [6,44] and acetylcholine [20] both in vitro and in vivo. More details of other reported neurotransmitter producing gut microbiota will discuss in the section of results. These studies implicate that neurotransmitters can modulated by gut microbiota.

\subsection{Neurotransmitters Imbalance Cause Mental Disorders}

Mental health disorders, such as depression and anxiety disorders, developed as a result of neurotransmitter imbalance in the brain. Depression is associated with an imbalance of serotonin, norepinephrine and dopamine $[23,45,46]$. It's thought that offbalance of dopamine may not only contribute to one's risk of developing depression [46] but also responsible for sleep disorders [27] and eating disorders [47,48]. Decreased serotonin metabolite level and increased norepinephrine are common in the pathophysiology of bipolar disorders [26]. The administration of a dopamine blocker altering the smoking addiction behaviors [49]. The abnormal metabolism of GABA leads to cognitive impairment [50,51]. Reduced level of GABA also give rise to cases of depression [52-54] and anxiety disorders [29,55]. Normal level of GABA helps to increase feelings of relaxation and decrease anxiety and mood disorders [56,57]. These studies implicate that changes in neurotransmitters occur in mental disorders.

\section{METHODOLOGY}

Gut microbiota influences mental health by regulating the level of neurotransmitters. To understand the relationship between gut microbiota, mental disorders and neurotransmitters, we did the bibliometric analysis basis of available literatures (Subsection 3.1). We classify the evidence of neurotransmitter modulate by gut microbiota into five levels by using evidence-based medical analysis (Subsection 3.2).

\subsection{Bibliometric Analysis}

Bibliometric data can be obtained through various search engines. In this study, we choose the Scopus database for literature retrieval. Using Scopus as our data source to retrieve "titles, abstracts and keywords" is reasonable because it is not only the largest abstract and citation database of peer-reviewed literature but also provides a comprehensive overview of the world's research outputs. The resources of Scopus more accurate and comprehensive than other 


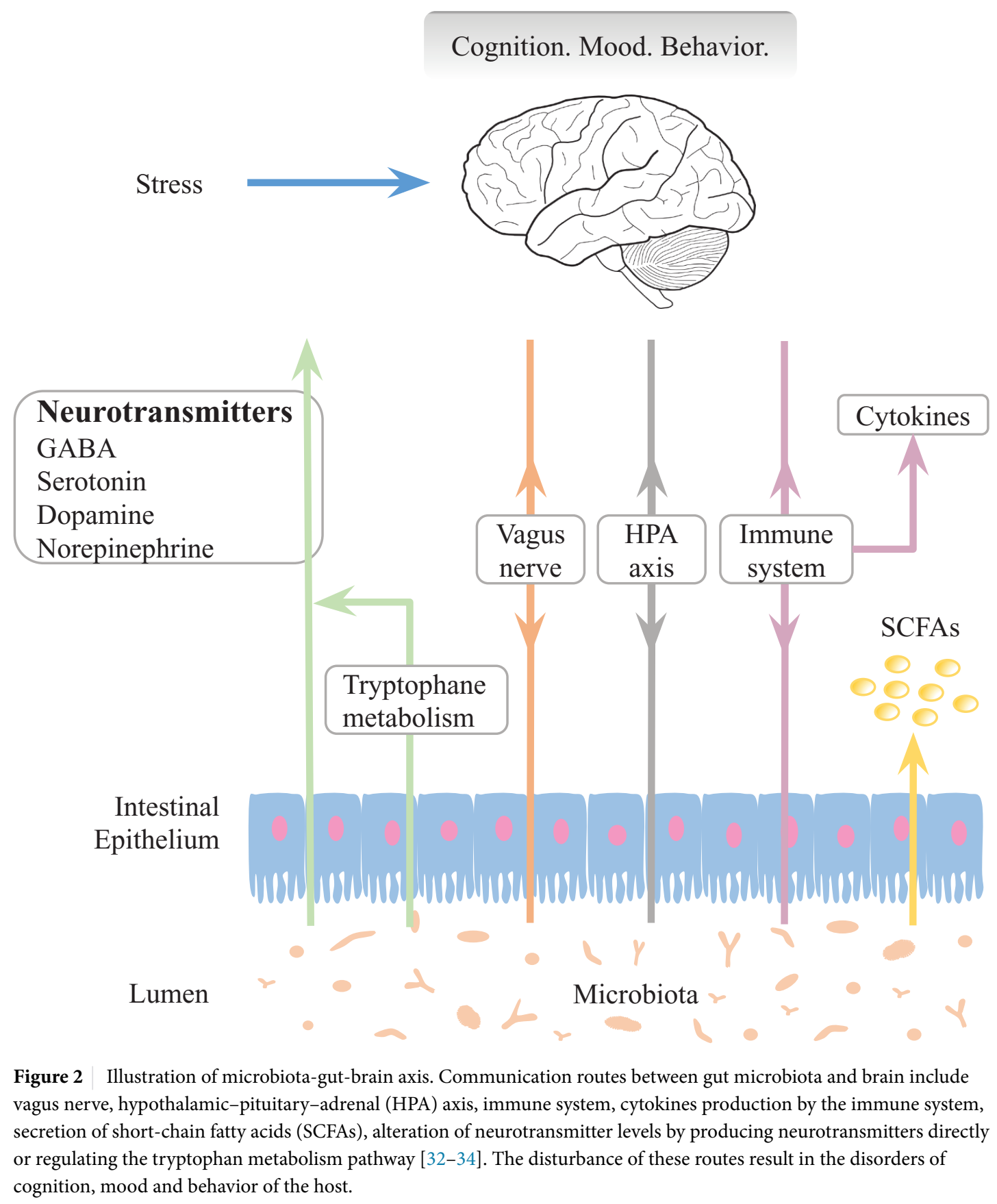

alternatives such as PubMed, Web of Science and Google Scholar [58-60]. The Elsevier Scopus's API ${ }^{1}$ is a Python library which easily to pull, cache and extract data from the Scopus database [61]. In this paper, we review the articles on the topic of gut microbiota and neurotransmitters with the extracted data from the Scopus database (Figure 3).

Scopus searches conducted on 21 June 2019 retrieve 8027 articles that study the association between neurotransmitters and mental disorders (Figure 3). It's well known that neurotransmitters play a role in maintaining mental health conditions. The impact of gut microbiota on mental health is a new research topic recently, especially in the past two or three years. A total of 445 articles

\footnotetext{
${ }^{1}$ https://github.com/pybliometrics-dev/pybliometrics
}

indicate a steady growth and an exponential increase in publication numbers (Figure 4). The data on the connection of gut microbiota and neurotransmitter also showing a similar trend with 422 articles (Figure 5). There are 100 articles published in the past ten years to investigate the interaction between gut microbiota, neurotransmitters and mental disorders (Figure 6). The influence of gut microbiota on mental health by regulating neurotransmitters needs to further explore (Figure 4).

\subsection{Hierarchy of Evidence Strength}

To systematically overview the updated studies of the association between gut microbiota and neurotransmitters, related articles were identified by using the Scopus retrieval. We critically appraised and 


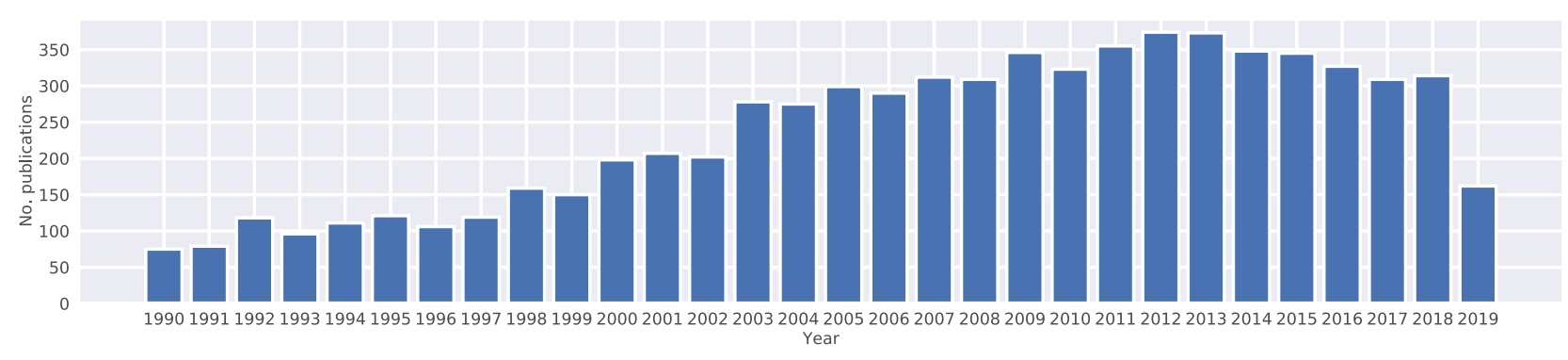

Figure 3 The number of publications per year on the topic of "neurotransmitters and mental disorders." We search the articles in Scopus database with the combination in the code: title-abs-key ("neurotransmitter" and ("gamma-aminobutyric acid (GABA)" or "serotonin" or "5-HT" or "dopamine" or "norepinephrine") and ("mental health" or "mental disorder" or "mood disorder" or "depression" or "anxiety" or "eating disorder" or "major depressive disorder")).

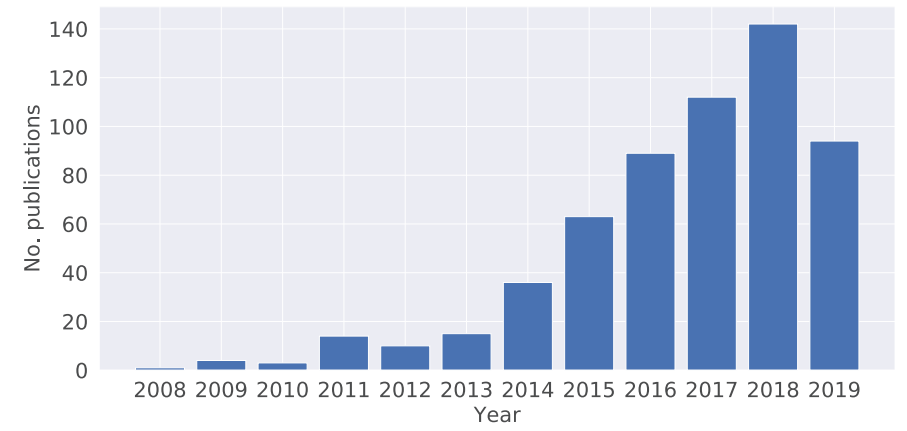

Figure 4 The number of publications per year on the topic of "gut microbiota and mental disorders." We search the articles in Scopus database with the combination in the code: title-abs-key (" "gut flora" or "gut microbiota" or "intestinal bacteria") and ("mental disorder" or "mood disorder" or "depression" or "major depressive disorder" or "anxiety or "eating disorder")).

classified the evidence hierarchy of these relevant articles in accordance with the strength of the randomized controlled trials (RCTs) design (Table 1) [62]. In medicine, levels of evidence arranged in a ranking system used in evidence-based practices to describe the strength of the results measured in a clinical trial or research study [63]. The design of a study (such as a case report for an individual patient or a double-blinded RCT) and the endpoints measured (such as survival or quality of life) affect the strength of evidence [64]. In this paper, we classified the articles into five levels (Table 1) in terms of the strength and reliability of evidence. We assorted the final conclusions into four levels (Table 2) on the basis of evidence analysis results [65]. A comprehensive list provided in this paper does not only contains representative neurotransmitters producing gut microbiota strains but also includes the gut microbiota strains which can be growth-regulated by neurotransmitters (Table 3 ). The full name of the gut microbiota strains listed in Figure 7.

\section{RESULTS}

Neurotransmitters (include serotonin, dopamine, norepinephrine, GABA, histamine and acetylcholine) have been implicated most often in etiological studies of mental disorders [66]. In this paper, we focus on these neurotransmitters which are the possible

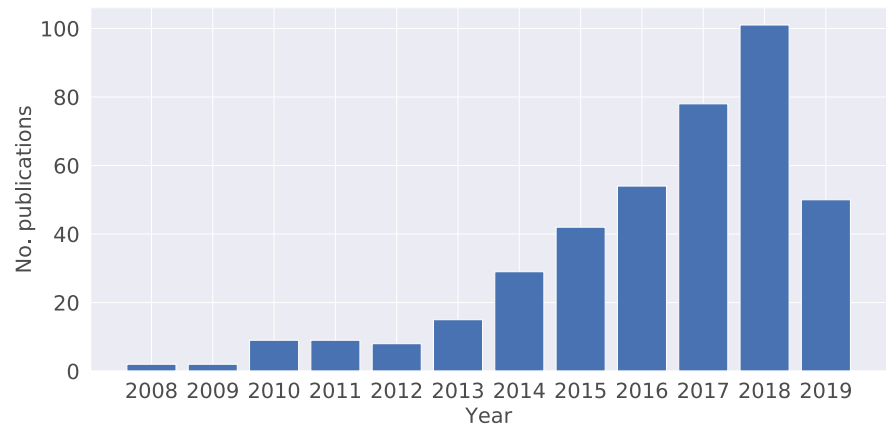

Figure 5 The number of publications per year on the topic of "gut microbiota and neurotransmitters." We search the articles in Scopus database with the combination in the code: title-abs-key (("gut flora" or "gut microbiota" or "intestinal bacteria") and ("neurotransmitter" or "serotonin" or "5-HT" or "dopamine" or "norepinephrine" or "gamma-aminobutyric acid (GABA)")).

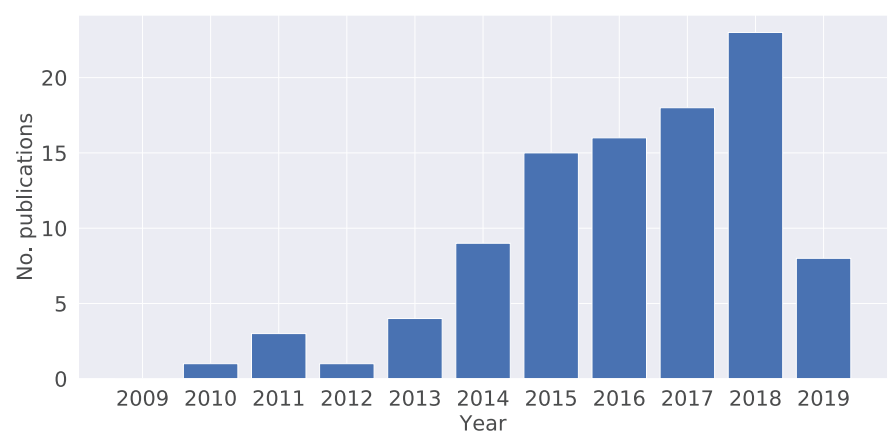

Figure 6 The number of publications per year on the topic of "gut microbiota, mental disorders and neurotransmitters." We search the articles in Scopus database with the combination in the code: title-abs-key (("gut flora" or "gut microbiota" or"intestinal bacteria") and ("mental disorder" or "mood disorder" or "depression" or "major depressive disorder" or "anxiety" or "eating disorder") and ("gamma-aminobutyric acid (GABA)" or "serotonin" or "5-HT" or "dopamine" or "norepinephrine")).

mediators between gut microbiota and mental disorders. We summarized the evidence details of the association between gut microbiota and neurotransmitters as shown in Table 3. The taxonomy of gut microbiota strains are shown in Figures 7 and 8. 
Table 1 Hierarchy of evidence based on the strength of randomized controlled trials (RCTs) design.

\begin{tabular}{ll}
\hline Level & Design of Study \\
\hline 1 & $\begin{array}{c}\text { Evidence obtained from a systematic review or at least } \\
\text { one RCTs } \\
\text { Evidence obtained from well-designed pseudo-RCTs of } \\
\text { appropriate size } \\
\text { Evidence from well-designed trials without randomization, } \\
\text { single group pre-post, cohort, time-series studies }\end{array}$ \\
3 & $\begin{array}{c}\text { Evidence obtained from case series or nonexperimental } \\
\text { studies from more than one center or research group }\end{array}$ \\
5 & $\begin{array}{c}\text { Opinions of authorities, based on clinical experience, } \\
\text { descriptive studies or reports of expert committees }\end{array}$ \\
\hline
\end{tabular}

Table 2 Classification of conclusions based on evidence analysis.

\begin{tabular}{ll}
\hline Level & Conclusions Based on Literature Analysis \\
\hline A & $\begin{array}{c}\text { Based on one Level } 1 \text { systematic review or research or at } \\
\text { least two independent Level } 2 \text { evidence }\end{array}$ \\
B & Based on one Level 2 evidence or at least two independent \\
& Level 3 evidence \\
C & Based on one Level 3 evidence or at least two independent \\
D & Level 4 evidence \\
\hline
\end{tabular}

\subsection{Serotonin}

As a neurotransmitter in the central nervous system, serotonin takes part in the regulation of many physiological functions, including sleep [89], appetite [90], sexual behavior [91], mood and cognition [92]. Many scientists believe that an imbalance of serotonin influences mood in a way that leads to depression, which called the "serotonin hypothesis" of clinical depression [93]. It's possibly related to less serotonin release or too fewer serotonin receptors, impaired serotonin receptor-mediated signal transduction, or a shortage in tryptophan, the chemical from which serotonin is made [94-96]. Serotonin has a well-confirmed role in the regulation of eating behaviors. Increased serotonin neurotransmission results in reduced eating behaviors of animals and humans, whereas reducing serotonin activity precipitates compulsive or binge eating [25]. Microbiota-dependent effects on gut serotonin significantly affect host physiology, modulating gastrointestinal motility and platelet function [16].

There are four Level 2 RCTs proved that the gut microbiota regulates the serotonin level in the host. Animal-like gut-brain module detection frequency in human gut-associated microbial genomes identify that B. cereus, B. oklahomensis, A. baumannii and paenibacillus spp. are act as potential serotonin producers. Administrating L. plantarum to a germ-free mouse model significantly increases the levels of both serotonin and dopamine in the striatum [7]. Fecal metabolites analysis showed that indigenous spore-forming of $B$. uniformis promote serotonin biosynthesis from enterochromaffin cells to the mucosa, lumen and circulating platelets [16]. The presence of $\mathrm{Cl}$. ramosum in gut promotes the secretion of serotonin in germ-free mice (67).

Eight Level 3 RCTs suggested that bacteria also produce serotonin in vitro. Serotonin is detected in histidine decarboxylase broth which contain the strains of $H$. alvei, K. pneumoniae and M. morganii [17], respectively. During the late growth phase of E. coli, the M-9 or LB culture medium of $E$. coli contained nanomolar of serotonin that is sufficient for animal/human receptors to bind [42]. Özoğul et al. proved that lactic acid bacteria can form the serotonin in arginine decarboxylase broth, the lactic acid bacteria including L. plantarum,
L. l. cremoris and L. l. lactis [43]. S. thermophilus has the ability to increase the concentration of serotonin in its growth medium [19]. C. albicans is the most common fungus species and member of the human gut microbiota. On one hand, it coats on the lining of the intestinal tract and suppresses the gut ability to produce serotonin [68]. On the other hand, serotonin has anti-fungal activity against Candida spp. in vitro [68]. Other fungi C. guilliermondii [69] and $S$. cerevisiae [71], as well as bacteria E. faecalis [69] and R. rubrum [70], can be growth-stimulated by serotonin. In a word, gut microbiota has the ability to regulate biosynthesis of serotonin.

\subsection{Dopamine}

Mental disorders are complex conditions caused by a number of factors. Dopamine, similar to serotonin, plays a part in controlling the movement of a person, as well as their emotional response [97]. The right balance of dopamine is vital for both physical and mental well-being. Multiple sources of evidence support that a dopamine deficiency related to certain medical conditions, such as depression [98] and Parkinson's disease [99]. Low dopamine can be a major contributor to depressive symptoms [98]. As we mentioned, the level of dopamine significantly increased in a germ-free mouse that carries with L. plantarum strain [7]. B. oklahomensis has a positive correlation with the synthesis of dopamine metabolite 3,4-dihydroxyphenylacetic acid [2]. Substantial contents of free dopamine and norepinephrine were detected in the gut lumen of either specific pathogen-free or germ-free mice with Clostridium species [18]. In addition to serotonin, Özoğul et al. certified that $H$. alvei, K. pneumoniae and M. morganii able to generate dopamine in histidine decarboxylase broth [17]. Similar to these bacteria, E. coli can also produce serotonin and dopamine in its culture medium [42,72]. Tsavkelova et al. found that the family of Bacillus are potential bacteria to produce dopamine [72]. This was confirmed by Lyte et al. at 2011 [73]. In addition, P. vulgaris, $S$. aureus and $S$. marcescens strains also have the ability to secrete dopamine [72]. The proliferation of $S$. cerevisiae EPF cells on solid maltose-peptone-yeast extract medium was growth stimulated by the addition of dopamine, serotonin or histamine [71]. The infectious spectrum of $Y$. enterocolitica is principally in the gut. The catecholamine responsiveness in Y. enterocolitica is limited to norepinephrine and dopamine [74]. E. coli and S. enterica were both response to these too neurotransmitters [74]. In brief, gut microbiota plays a key role in promoting the production of dopamine in the host.

\subsection{Norepinephrine}

Norepinephrine plays a determinant role in executive functioning regulating cognition, motivation and intellect $[23,100]$. In the 1960s, the "Catecholamine hypothesis" was a popular explanation for why people developed depression. This hypothesis suggested that a deficiency of the neurotransmitter norepinephrine in certain areas of the brain was responsible for creating a depressed mood [101]. Recently, more and more studies suggested that depressed persons have low levels of norepinephrine indeed [23]. A number of bacteria had been reported to yield norepinephrine. Clostridium increased the free norepinephrine in the gut lumen of both germfree and specific pathogen-free mice, the concentration is lower in the former than the latter one [18]. Norepinephrine was also yield by E. coli in its growth medium [42]. B. mycoides and B. subtilis, 
Table 3 Neurotransmitters-modulating gut microbiota. "Levels" show the hierarchy of evidence (Table 1). " + " indicates that gut microbiota increase the level of neurotransmitter. "P" means the neurotransmitter promote the growth of gut microbiota, whereas "I" means the inhibition. Full strain names listed in Figure 7.

\begin{tabular}{|c|c|c|c|c|}
\hline Neurotransmitters & Levels & Gut Microbiota Strains & Regulate & References \\
\hline \multirow[t]{2}{*}{ Serotonin } & 2 & $\begin{array}{l}\text { B. cereus, B. oklahomensis, A. baumannii, } \\
\text { Paenibacillus spp. } \\
\text { L. plantarum } \\
\text { B. uniformis } \\
\text { Cl. ramosum } \\
\end{array}$ & $\begin{array}{l}+ \\
+ \\
+ \\
+\end{array}$ & $\begin{array}{l}\text { Valles et al. [2] } \\
\text { Liu et al. [7] } \\
\text { Yano et al. [16] } \\
\text { Mandic et al. [67] }\end{array}$ \\
\hline & 3 & $\begin{array}{l}\text { H. alvei, K. pneumoniae, M. morganii } \\
\text { E. coli } \\
\text { C. albicans } \\
\text { L. l. cremoris, L. l. lactis, L. plantarum } \\
\text { S. thermophilus } \\
\text { E. faecalis, C. guilliermondii } \\
\text { R. rubrum } \\
\text { S. cerevisiae }\end{array}$ & $\begin{array}{l}\mathrm{I} \\
\mathrm{P} \\
\mathrm{P} \\
\mathrm{P}\end{array}$ & $\begin{array}{l}\text { Özoğul [17] } \\
\text { Shishov et al. [42] } \\
\text { Mayr et al. [68] } \\
\text { Özoğul et al. [43] } \\
\text { Gezginc et al. [19] } \\
\text { Strakhovskaia et al. [69] } \\
\text { Oleskin et al. [70] } \\
\text { Malikina et al. [71] }\end{array}$ \\
\hline \multirow[t]{2}{*}{ Dopamine } & 2 & $\begin{array}{l}\text { B. oklahomensis } \\
\text { L. plantarum } \\
\text { Clostridium spp. }\end{array}$ & $\begin{array}{l}+ \\
+ \\
+\end{array}$ & $\begin{array}{l}\text { Valles et al. [2] } \\
\text { Liu et al. [7] } \\
\text { Asano } \text { et al. [18] }\end{array}$ \\
\hline & 3 & $\begin{array}{l}\text { H. alvei, K. pneumoniae, M. morganii } \\
\text { E. coli } \\
\text { S. cerevisiae } \\
\text { S. thermophilus } \\
\text { B. cereus, B. mycoides, B. subtilis, E. coli } \\
\text { P. vulgaris, S. aureus, S. marcescens } \\
\text { Bacillus spp. } \\
\text { Y. enterocolitica, S. enterica, E. coli } \\
\end{array}$ & $\begin{array}{l}+ \\
+ \\
+ \\
+ \\
+\end{array}$ & $\begin{array}{l}\text { Özoğul [17] } \\
\text { Shishov et al. [42] } \\
\text { Malikina et al. [71] } \\
\text { Gezginc et al. [19] } \\
\text { Tsavkelova } \text { et al. [72] } \\
\text { Lyte et al. [73] } \\
\text { Freestone et al. [74] }\end{array}$ \\
\hline \multirow[t]{2}{*}{ Norepinephrine } & 2 & Clostridium spp. & + & Asano et al. [18] \\
\hline & 3 & $\begin{array}{l}\text { E. coli } \\
\text { B. mycoides, B. subtilis, } P \text {. vulgars, } S \text {. marcescens } \\
\text { Y. enterocolitica, S. enterica, E. coli } \\
\text { P. aeruginosa }\end{array}$ & + & $\begin{array}{l}\text { Shishov et al. [42] } \\
\text { Tsavkelova et al. [72] } \\
\text { Freestone et al. [74] } \\
\text { Hegde et al. [75] }\end{array}$ \\
\hline \multirow[t]{3}{*}{ GABA } & 1 & $\begin{array}{l}\text { Oscillibacter spp. } \\
\text { Bacteroides, Parabacteroides, Escherichia. }\end{array}$ & $\begin{array}{l}+ \\
+\end{array}$ & $\begin{array}{l}\text { Naseribafrouei et al. [37] } \\
\text { Strandwitz et al. [76] }\end{array}$ \\
\hline & 2 & $\begin{array}{l}\text { Coprococcus spp. } \\
\text { L. reuteri } \\
\text { B. dentium } \\
\text { B. dentium }\end{array}$ & $\begin{array}{l}+ \\
+ \\
+ \\
+\end{array}$ & $\begin{array}{l}\text { Valles et al. [2] } \\
\text { Kunze } \text { et al. [44] } \\
\text { Vadder } \text { et al. }[77] \\
\text { Pokusaeve } \text { et al. }[78]\end{array}$ \\
\hline & 3 & $\begin{array}{l}\text { L. rhamnosus } \\
\text { L. brevis, B. dentium } \\
\text { L. brevis } \\
\text { L. buchneri } \\
\text { L. paracasei } \\
\text { L. plantarum, L. rhamnosus, L. delbrueckii } \\
\text { M. purpureus } \\
\text { S. salivarius }\end{array}$ & $\begin{array}{l}+ \\
+ \\
+ \\
+ \\
+ \\
+ \\
+ \\
+\end{array}$ & $\begin{array}{l}\text { Bravo et al. [6] } \\
\text { Barrett et al. [79] } \\
\text { Wu et al. [80] } \\
\text { Cho et al. [81] } \\
\text { Komatsuzaki et al. [82] } \\
\text { Siragusa et al. [83] } \\
\text { Su et al. [84] } \\
\text { Yang et al. }[85] \\
\end{array}$ \\
\hline \multirow[t]{2}{*}{ Histamine } & 2 & $\begin{array}{l}\text { A. baumannii, F. varium, B. fragilis, F. ulcerans } \\
\text { M. morganii }\end{array}$ & $\begin{array}{l}+ \\
+ \\
\end{array}$ & $\begin{array}{l}\text { Valles et al. [2] } \\
\text { Kim et al. [86] }\end{array}$ \\
\hline & 3 & $\begin{array}{l}\text { S. thermophilus } \\
\text { S. cerevisiae } \\
\text { E. coli } \\
\text { L. vaginalis }\end{array}$ & $\begin{array}{l}+ \\
+ \\
+\end{array}$ & $\begin{array}{l}\text { Gezginc et al. [19] } \\
\text { Malikina et al. [71] } \\
\text { Scheffer et al. [87] } \\
\text { Diaz et al. }[88]\end{array}$ \\
\hline \multirow[t]{2}{*}{ Acetylcholine } & 2 & A. hydrogeniformans & + & Valles et al. [2] \\
\hline & 3 & L. plantarum & + & Stanaszek et al. [20] \\
\hline
\end{tabular}

both belong to the genius of Bacillus, have the ability to secrete norepinephrine [72]. The author also found P. vulgaris and S. marcescens have the same potential [72]. Norepinephrine specific induced the growth of S. enterica, Y. enterocolitica and E. coli [74]. In addition, norepinephrine also promoted the growth, virulence factor production, and swimming motility of $P$. aeruginosa in a concentrationdependent manner [75]. In short, gut microbiota plays a critical role in the generation of norepinephrine.

\subsection{Gamma-Aminobutyric Acid}

GABA constitutes a major inhibitory neurotransmitter in the sympathetic nervous system and has antidepressant [102], antihypertensive [103] and anti-diabetic effects in humans [104]. Numerous experiments and clinical data indicate that the decreased GABA function was accompanied by depressed or manic mood states [105]. Other disorders such as psychiatric disease, sleep disorders, 


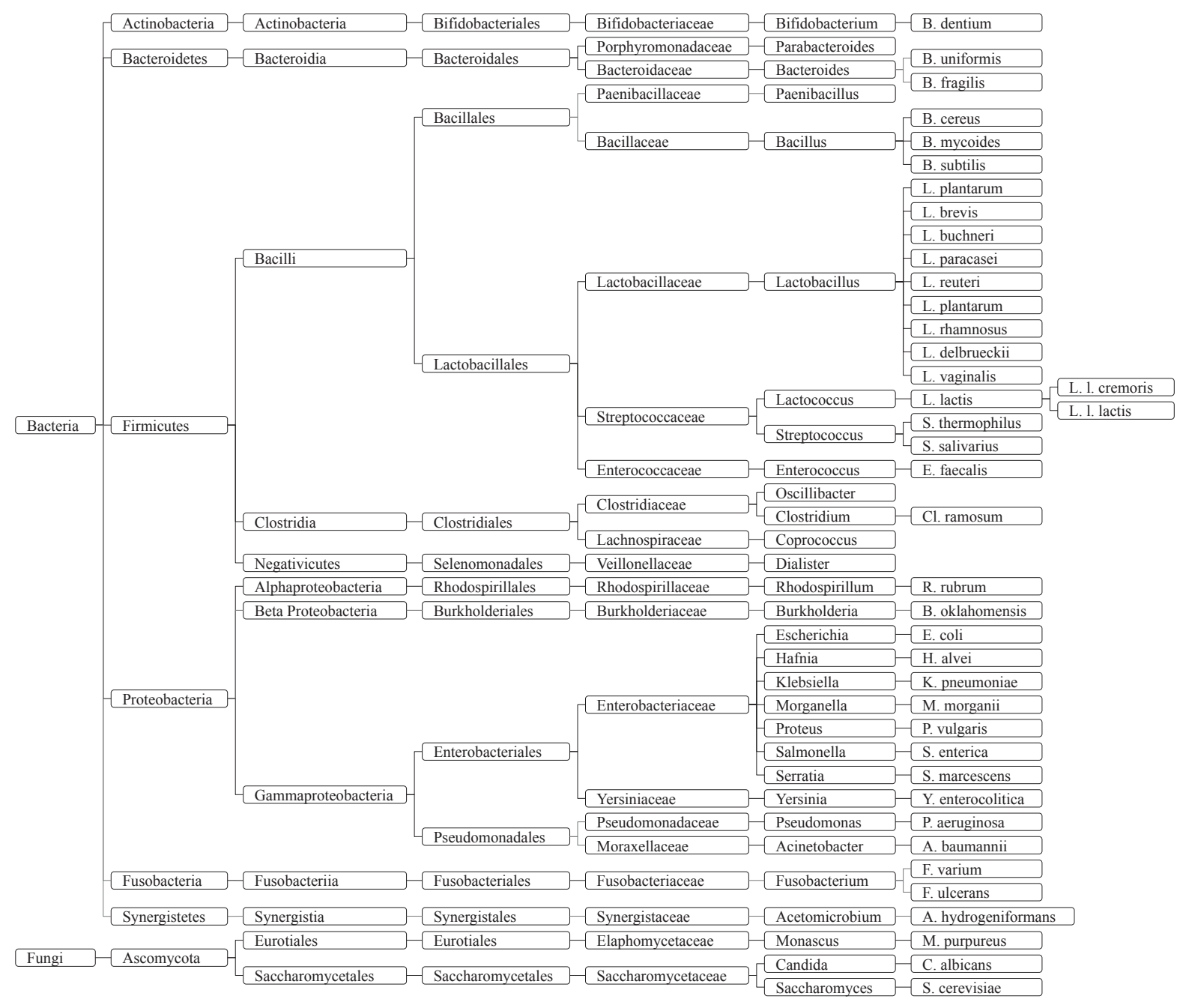

\begin{tabular}{l|l} 
Figure 7 & Taxonomy of gut microbiota that can affect or be affected by neurotransmitters.
\end{tabular}

drug and alcohol addiction have been related to the chaos of GABAergic function in the brain [106]. Animal models of depression showed regional brain GABA deficits and GABA agonists have antidepressant activity [105]. A variety of GABA-producing intestinal bacteria have been found, the Oscillibacter-type strain has valeric acid (a homolog of neurotransmitter GABA) as its main metabolic end product. Oscillibacter has previously been shown to be associated with induced stress in mice [37]. The transcriptome analysis of human stool samples from healthy individuals proved that the GABA-producing pathways are actively expressed by species of Bacteroides, Parabacteroides and Escherichia [76]. Gutbrain module analysis of fecal meta-genomes indicated that the Coprococcus spp. has a potential role in microbial GABA production in depression patients [2]. Commensal B. dentium can produce GABA via enzymatic decarboxylation of glutamate by GadB [78]. It stimulated the generation of GABA in germ-free mice [77], sprague-dawly rats [78] and monosodium glutamate medium [79]. The addition of $L$. brevis to the gut microbiota increased the GABA concentration in the fermented fecal slurry at physiological pH [79]. Other GABA-producing Lactobacillus strains include L. reuteri [44], L. brevis [80], L. buchneri [81], L. paracasei [82], L. plantarum [83], L. rhamnosus [6,83] and L. delbrueckii [83]. GABA formed by S. salivarius subsp. via submerged fermentation
[85]. In addition to bacteria, GABA also can be produced by fungi, such as Monascus spp [84]. During solid-state fermentation, M. purpureus improve the production of GABA significantly [84]. All in all, these studies reveal that gut microbiota has the capability to produce GABA both in vivo and in vitro.

\subsection{Histamine}

Abnormally of histamine in the brain lead to mental disorders. Intestinal bacteria secrete histamine and release histamine from human basophil leukocytes and mast cells which influence the host immunological processes $[107,108]$. Two Level 2 RCTs proved that M. morganii, A. baumannii, F. varium and B. fragilis were four types of histamine secreting bacteria $[2,86]$. S. thermophilus isolates had an ability to produce twelve different biogenic amines, including seroptonin and dopamine, in histidine broth and lysine decarboxylase broth [19]. Bacterial adherence and hemolysin production of E. coli induced histamine release from cells [87]. L. vaginalis was an another potential histamine-producing strain [88]. The addition of histamine can stimulate the proliferation of S. cerevisiae EPF cells on solid maltose-peptone-yeast extract medium [71]. To sum up, gut microbiota also contributes to elevate the histamine level. 


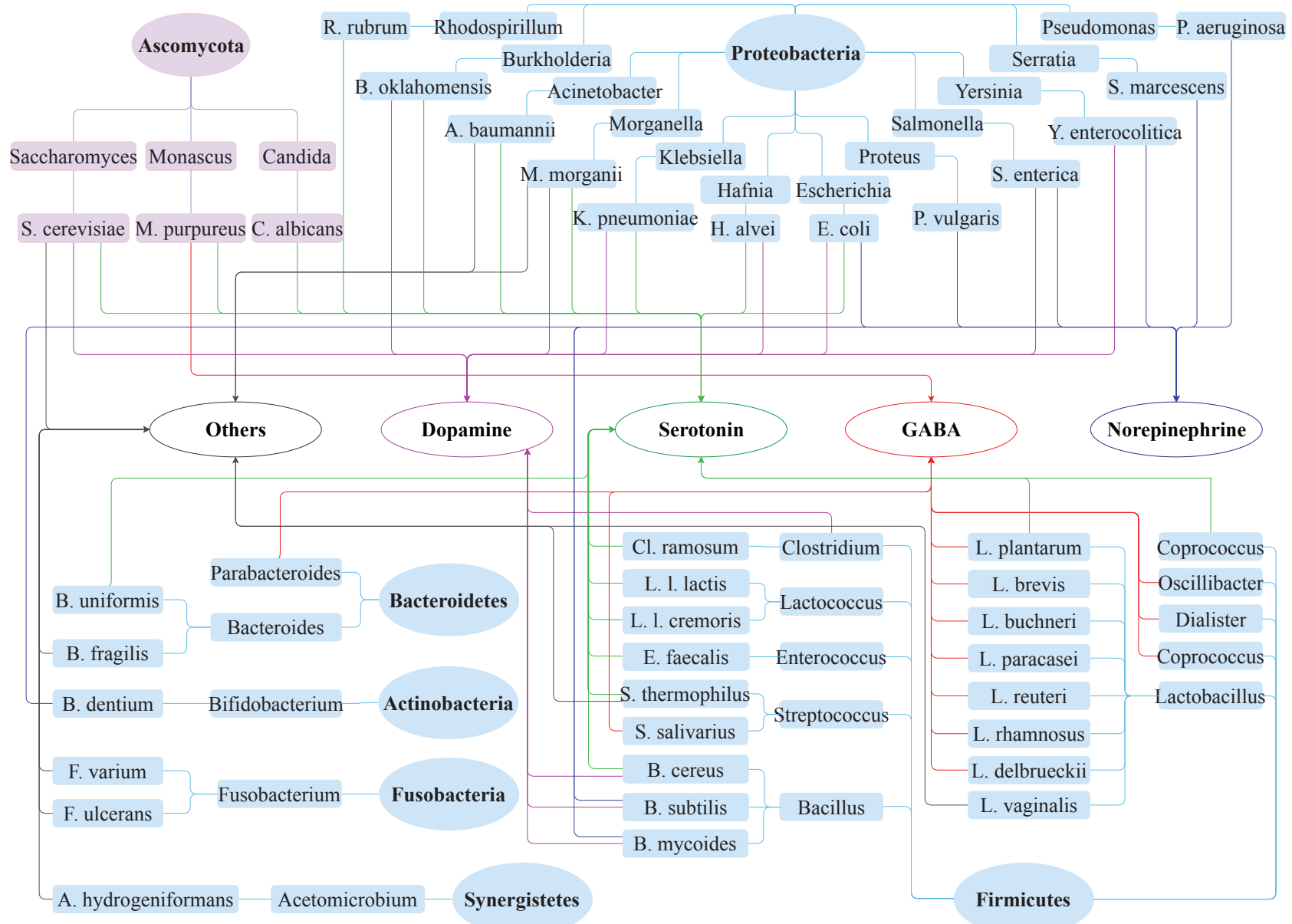

Figure 8 Neurotransmitters modulation by gut microbiota. The gut microbiota include six phyla of bacteria and one phylum of fungi. Light blue background ellipses and oblongs indicate the species relationship of the bacteria, and light purple backgrounds ellipse and oblongs represent the fungi. Connection lines with different colors are used to show the link between gut microbiota and neurotransmitters: dopamine (pink), serotonin (green), Norepinephrine (blue), gamma-aminobutyric acid (GABA) (red) and others (gray). The "others" contain histamine and acetylcholine.

\subsection{Acetylcholine}

Acetylcholine serves as a primarily excitatory neurotransmitter in the central nervous system. It plays a role in arousal, memory and learning. It works together with dopamine to enable smooth movements. Acetylcholine systems had a crucial role in the regulation of the sleep-waking cycle [109]. Increased acetylcholine signaling led to symptoms of depression and anxiety in both human and animal models [110]. A. hydrogeniformans promoted the synthesis of acetylcholine in host [2]. Stanaszek et al. successfully extracted acetylcholine from the growth medium of L. plantarum strain [20]. In conclusion, gut microbiota induces the synthesis and release of acetylcholine in the host.

\subsection{The Triangle Relationship between Gut Microbiota, Mental Disorders and Neurotransmitters}

Gut microbiota impacts on mental health by regulating neurotransmitters level in the host. Such an impact may not just be a linear relationship, but a bidirectional triangle relationship (Figure 9). Change the composition and diversity of gut microbiota cause mental disorders in the host [5]. Conversely, mental disorder can tamp down beneficial bacteria in the host, decrease the overall diversity of the gut microbiome and promote the overgrowth of harmful bacteria [111]. Gut microbiota has the ability to promote the production of neurotransmitters [7]. On the contrary, neurotransmitters can affect the growth and toxicity of gut microbiota [69]. It's well known that interruption of neurotransmitters involved in the development of mental disorders [21]. On the other side, prolonged periods of stress can deplete neurotransmitters levels leading to neurotransmitters imbalance [112]. It means that mental disorders may lead to an imbalance of neurotransmitters in the host. Taken together, these studies implicate a potential triangle relationship between gut microbiota, neurotransmitter, and mental disorders (Figure 9).

\section{DISCUSSION}

Gut microbiota has impacts on mental disorders though neurotransmitter-mediated pathways $[2,6,7]$. Increasing evidences suggest an interaction between the gut microbiota, the gut and the brain which recognized as the microbiota-gut-brain axis (Figure 2) 


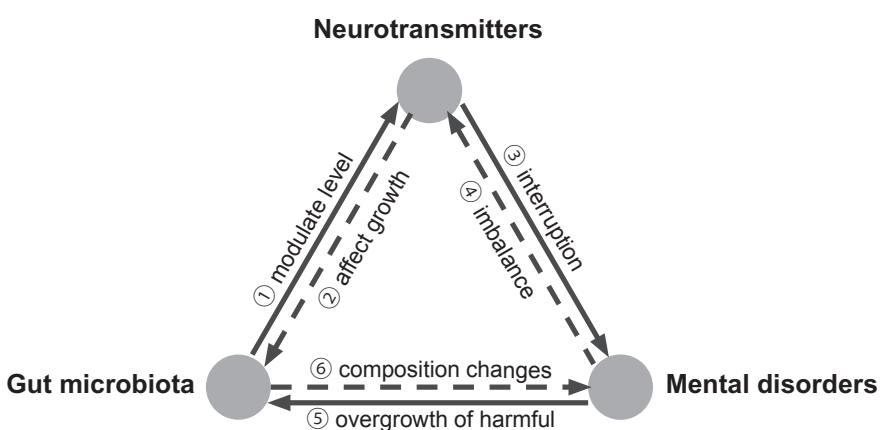

Figure 9 The triangle relationship between gut microbiota, neurotransmitters and mental disorders. Gut microbiota modulates the level of neurotransmitters [7] and conversely neurotransmitters affect the growth of gut microbiota [69]. Disturbance of neurotransmitters involved in the mental problems [21] and conversely mental disorders cause an imbalance of neurotransmitters in host [112]. Mental disorder cause an overgrowth of bad microbiota [111] and conversely change the composition of gut microbiota cause mental disorders [5].

$[113,114]$. The presence or absence of conventional gut microbiota influenced the development of behaviors, which accompanied by neurochemical changes in the brain [115]. The Coprococcus and Oscillibacter were two type strains involve in depression and both can promote GABA production [2,37]. The Coprococcus was consistently depleted which company with increased GABA levels in the blood in individuals with depression [2]. Ingestion of L. plantarum induced changes in emotional behaviors that correlated with the increase of serotonin, dopamine and norepinephrine in the striatum [7]. Lactobacillus strains reduced the anxiety- and depression-related behaviors through GABA signaling in a mouse model $[6,32]$. Taken together, these studies proved that neurotransmitters work as mediating pathways in the influences of gut microbiota on mental health conditions.

The interaction between gut microbiota and neurotransmitters is a bidirectional act. A lot of studies focus on the capacity of gut microbiota to produce the neurotransmitters. At the same time, there are several studies concerning the ability of specific neurotransmitters to affect the growth of gut microbiota. Some studies have demonstrated that the in vitro growth of a number of gut microbiota species can be increased in the presence of one or more of the neurotransmitters. As we listed in the Table 3, serotonin can be secreted by $C$. albicansis and it also has anti-fungal activity against Candida spp. [68]. E. coli yield norepinephrine and dopamine in the growth medium [42] and it's growth specific induced by these two neurotransmitters [74]. S. cerevisiae can be growth-stimulated by serotonin, dopamine and histamine [71]. In addition, serotonin stimulates the growth of E. faecalis [69] and R. rubrum [70]. The hormone norepinephrine increased the growth, virulence factor production and swimming motility of $P$. aeruginosa in a concentration-dependent manner [75]. To sum up, gut microbiota and neurotransmitters regulated by each other.

Mental disorders can be prevented and treated by altering the composition and diversity of gut microbiota. Recent studies show that the absence of gut microbiota during early life affect the antianxiety behaviors of mice [116]. Transplanting the gut microbiota from depressed patients to germ-free animals induced depressivelike behaviors of the host $[5,117,118]$. The effect of gut microbiota on depressive-like behaviors abolished by using the antidepressants [119]. Gut microbiota also associated with the pathogenesis of schizophrenia [120], eating disorder [9] and sleep disorder [8]. Various strategies, include fecal microbiota transplantation [5], antibiotic use [121], probiotic treatment [7] and germ-free models [38], have been used by researchers to explore the influence of gut microbiota on mental disorders. These methods provide the support to research on the composition changes of gut microbiota that happened in the mental disorders of animals. All told, modification of gut microbiota through diet or other strategies have significant utility in preventing and treating mental disorders.

\section{RECOMMENDATION}

Multiple neurotransmitter systems play parts in mental disorders and tend to contribute to specific symptoms. To be sure, the neurotransmitters are involved in mental disorders, but it's not as simple as one being too low and another too high. In this paper, we come to conclude that neurotransmitters as messenger molecules mediated in the influence of gut microbiota on mental health. Further work is needed to explore how gut microbiota regulating the level of the neurotransmitters. The potential mechanism very likely involves neurotransmitters and their receptors [122], as they are produced by and move from one system to another linking the brain, gut, immune system and microbiota. The communication between the central nervous system and bacteria relies on the presence of neurotransmitter receptors on bacteria [123]. The binding sites for enteric neurotransmitters produced by the host are present in bacteria and can influence the function of components of the microbiota [123]. That means the neurotransmitter receptors may say is a key point to figure out how gut microbiota regulates neurotransmitters production and metabolism.

Gut microbiota is an appealing therapeutic target for treating mental disorders. Resident gut microbiota is an important contributor to health. The presence of healthy and diverse gut microbiota is important for normal behavioral, cognitive and emotional management $[124,125]$. Compare to healthy individuals, major depressive disorder patients showed significant changes in gut microbial diversity and composition [5]. That means the patients with mental disorders may be cured by altering the composition of gut microbiota. Ingestion of appropriate amounts and types of probiotics might confer a mental health benefit by affecting gut microbiota of the host. It has been reported that the consumption of probiotics, such as L. plantarum, reduced the anxiety and depression-related behaviors [6,32]. Many probiotics often produce essential neurotransmitters that affect mood, motivation and cognition. Taken together, the gut microbiota is a potential therapeutic target for mental disorders. More clinical trials need to test to develop proper treatment programs for individuals.

The establishment of good gut microbiota during early life may prevent the occurrence of mental disorders. The gut microbiota plays an important role in the maturation of the immune system, especially in the early stage of life, during infant growth and development [126]. It has been assumed that the process of colonization and development of gut microbiota in early life is linked to diseases in later life. The absence of commensal microbiota during early life markedly affects the neurotransmitters system in the hippocampal 
of mice and how they respond to anxiety [116]. As critical modulators of the enteric nervous system and central nervous system development and function, neurotransmitters substantial influence on the microbiota-gut-brain axis. Therefore, establish good intestinal microbiota during early life might help prevent children at risk of developing mental disorders.

\section{CONCLUSION}

There is a correlation between the quality of life and the potential ability of the gut microbes to synthesize the neurotransmitters. Gut microbiota has an impact on mental disorders through neurotransmitter-mediated pathways (Level A). Microbial-derived neurotransmitters interact with the human central nervous system to alter the host's behavior or disease risk. We summarized the key evidence of gut microbiota-mediated influence on neurotransmitters, including serotonin, dopamine, norepinephrine, GABA, histamine and acetylcholine. We found that the interaction between gut microbiota and neurotransmitters is a bilateral act (Level A). On one hand, gut microbiota promotes the production of neurotransmitters in the host. On the other hand, gut microbiota conversely growth stimulated by these chemicals. Together with mental disorders, gut microbiota and neurotransmitters formed a bidirectional triangle relationship (Level B). It implicate that gut microbiota is an appealing therapeutic target for treating mental disorders (Level A). The establishment of intestinal microbiota during early life can prevent the occurrence of mental disorders (Level A). The diet continues to have a significant impact on microbiota composition throughout the lifespan of the host. People who have experienced mental disorders may be cured in the future by altering the gut microbiota, by taking probiotics or changing dietary.

\section{COMPETING INTERESTS}

The authors declare that they have no competing interests.

\section{AUTHORS' CONTRIBUTIONS}

T. Liu wrote the manuscript with contributions from all co-authors.

\section{Funding Statement}

Ting Liu is funded by the Chinese Scholarship Council under grant number 201707720743.

\section{ACKNOWLEDGMENTS}

The authors thank the Chinese Scholarship Council for supporting T. Liu's studies in The Netherlands. The authors thank the anonymous reviewers for their constructive remarks, and in particular for their suggestions on the discussion part, which greatly contributed to this paper.

\section{REFERENCES}

[1] H. Jiang, Z. Ling, Y. Zhang, H. Mao, Z. Ma, Y. Yin, et al., Altered fecal microbiota composition in patients with major depressive disorder, Brain Behav. Immun. 48 (2015), 186-194.
[2] M. Valles-Colomer, G. Falony, Y. Darzi, E.F. Tigchelaar, J. Wang, R.Y. Tito, et al., The neuroactive potential of the human gut microbiota in quality of life and depression, Nat. Microbiol. 4 (2019), 623-632.

[3] J.A. Foster, K.-A.M. Neufeld, Gut-brain axis: how the microbiome influences anxiety and depression, Trends Neurosci. 36 (2013), 305-312.

[4] J.R. Kelly, Y. Borre, C. O'Brien, E. Patterson, S.E. Aidy, J. Deane, P.J. Kennedy, et al., Transferring the blues: depression-associated gut microbiota induces neurobehavioural changes in the rat, J. Psychiatr. Res. 82 (2016), 109-118.

[5] P. Zheng, B. Zeng, C. Zhou, M. Liu, Z. Fang, X. Xu, et al., Gut microbiome remodeling induces depressive-like behaviors through a pathway mediated by the host's metabolism, Mol. Psychiatry. 21 (2016), 786.

[6] J.A. Bravo, P. Forsythe, M.V. Chew, E. Escaravage, H.M. Savignac, T.G. Dinan, J. Bienenstock, J.F. Cryan, Ingestion of lactobacillus strain regulates emotional behavior and central gaba receptor expression in a mouse via the vagus nerve, Proc. Nat. Acad. Sci. 108 (2011), 16050-16055.

[7] W.-H. Liu, H.-L. Chuang, Y.-T. Huang, C.-C. Wu, G.-T. Chou, S. Wang, Y.-C. Tsai, Alteration of behavior and monoamine levels attributable to lactobacillus plantarum ps128 in germ-free mice, Behav. Brain Res. 298 (2016), 202-209.

[8] R.P. Smith, C. Easson, S.M. Lyle, R. Kapoor, C.P. Donnelly, E.J. Davidson, E. Parikh, J.V. Lopez, J.L. Tartar, Gut microbiome diversity is associated with sleep physiology in humans, PloS One. 14 (2019), e0222394.

[9] E.M. Glenny, E.C. Bulik-Sullivan, Q. Tang, C.M. Bulik, I.M. Carroll, Eating disorders and the intestinal microbiota: mechanisms of energy homeostasis and behavioral influence, Curr. Psychiatry Rep. 19 (2017), 51.

[10] T. Liu, Z. Huang, Evidence-based analysis of neurotransmitter modulation by gut microbiota, in: H. Wang, S. Siuly, R. Zhou, F. Martin-Sanchez, Y. Zhang, Z. Huang (Eds.), International Conference on Health Information Science, Springer, Cham, Switzerland, 2019, pp. 238-249.

[11] M.D. Gershon, J. Tack, The serotonin signaling system: from basic understanding to drug development for functional gi disorders, Gastroenterology. 132 (2007), 397-414.

[12] N. Terry, K.G. Margolis, Serotonergic mechanisms regulating the gi tract: experimental evidence and therapeutic relevance, in: B. Greenwood-Van Meerveld (Eds.), Gastrointestinal Pharmacology, Springer, Cham, Switzerland, 2016, pp. 319-342.

[13] G. Eisenhofer, A. Aneman, P. Friberg, D. Hooper, L. Fandriks, H. Lonroth, B. Hunyady, E. Mezey, Substantial production of dopamine in the human gastrointestinal tract, J. Clin. Endocrinol. Metabol. 82 (1997), 3864-3871.

[14] R. Xue, H. Zhang, J. Pan, Z. Du, W. Zhou, Z. Zhang, Z. Tian, R. Zhou, L. Bai. Peripheral dopamine controlled by gut microbes inhibits invariant natural killer t cell-mediated hepatitis, Front. Immunol. 9 (2018), 2398.

[15] K. Sjögren, C. Engdahl, P. Henning, U.H. Lerner, V. Tremaroli, M.K. Lagerquist, F. Bäckhed, C. Ohlsson, The gut microbiota regulates bone mass in mice, J. Bone Mineral Res. 27 (2012), $1357-1367$.

[16] J.M. Yano, K. Yu, G.P. Donaldson, G.G. Shastri, P. Ann, L. Ma, C.R. Nagler, R.F. Ismagilov, S.K. Mazmanian, E.Y. Hsiao, Indigenous bacteria from the gut microbiota regulate host serotonin biosynthesis, Cell. 161 (2015), 264-276. 
[17] F. Özoğul, Production of biogenic amines by morganella morganii, klebsiella pneumoniae and hafnia alvei using a rapid hplc method, Eur. Food Res. Technol. 219 (2004), 465-469.

[18] Y. Asano, T. Hiramoto, R. Nishino, Y. Aiba, T. Kimura, K. Yoshihara, Y. Koga, N. Sudo, Critical role of gut microbiota in the production of biologically active, free catecholamines in the gut lumen of mice, Am. J. Physiol. Gastrointest. Liver Physiol. 303 (2012), G1288-G1295.

[19] Y. Gezginc, I. Akyol, E. Kuley, F. Özogul, Biogenic amines formation in streptococcus thermophilus isolated from home-made natural yogurt, Food Chem. 138 (2013), 655-662.

[20] P.M. Stanaszek, J.F. Snell, J.J. O’Neill, Isolation, extraction, and measurement of acetylcholine from lactobacillus plantarum, Appl. Envron. Microbiol. 34 (1997), 237-239.

[21] R. Mittal, L.H. Debs, A.P. Patel, D. Nguyen, K. Patel, G. O'Connor, et al., Neurotransmitters: the critical modulators regulating gut-brain axis, J. Cell. Physiol. 232 (2017), 2359-2372.

[22] P.L. Delgado, F.A. Moreno, Role of norepinephrine in depression, J. Clin. Psychiatry. 61 (2000), 5-12. https://www. psychiatrist.com/jcp/article/pages/2000/v61s01/v61s0102.aspx.

[23] C. Moret, M. Briley, The importance of norepinephrine in depression, Neuropsychiatr. Dis. Treat. 7 (2011), 9.

[24] J.R. Homberg, D. Schubert, P. Gaspar, New perspectives on the neurodevelopmental effects of ssris, Trends Pharmacol. Sci. 31 (2010), 60-65.

[25] J.E. Blundell, Serotonin manipulations and the structure of feeding behaviour, Appetite. 7 (1986), 39-56.

[26] L. Trevor Young, J.J. Warsh, S.J. Kish, K. Shannak, O. Hornykeiwicz, Reduced brain 5-ht and elevated ne turnover and metabolites in bipolar affective disorder, Biol. Psychiatry. 35 (1994), 121-127.

[27] J.M. Monti, D. Monti, The involvement of dopamine in the modulation of sleep and waking, Sleep Med. Rev. 11 (2007), 113-133.

[28] R. Hoehn-Saric, Neurotransmitters in anxiety, Arch. Gen. Psychiatry. 39 (1982), 735-742.

[29] P. Nuss, Anxiety disorders and gaba neurotransmission: a disturbance of modulation, Neuropsychiatr. Dis. Treat. 11 (2015), 165.

[30] J.F. Cryan, K.J. O'Riordan, C.S.M. Cowan, K.V. Sandhu, T.F.S. Bastiaanssen, M. Boehme, et al., The microbiota-gut-brain axis, Physiol. Rev. (2019), 1877-2013.

[31] T.C. Fung, C.A. Olson, E.Y. Hsiao, Interactions between the microbiota, immune and nervous systems in health and disease, Nat. Neurosci. 20 (2017), 145.

[32] P. Strandwitz, Neurotransmitter modulation by the gut microbiota, Brain Res. 1693 (2018), 128-133.

[33] T.G. Dinan, R.M. Stilling, C. Stanton, J.F. Cryan, Collective unconscious: how gut microbes shape human behavior, J. Psychiatr. Res. 63 (2015), 1-9.

[34] Y. Li, Y. Hao, B. Zhang, F. Fan, The role of microbiome in insomnia, circadian disturbance and depression, Front. Psychiatry. 9 (2018), 669.

[35] G. MacQueen, M. Surette, P. Moayyedi, The gut microbiota and psychiatric illness, J. Psychiatry Neurosci. JPN. 42 (2017), 75.

[36] P.P. Roy-Byrne, K.W. Davidson, R.C. Kessler, G.J.G. Asmundson, R.D. Goodwin, L. Kubzansky, et al., Anxiety disorders and comorbid medical illness, Focus. 6 (2008), 467-485.
[37] A. Naseribafrouei, K. Hestad, E. Avershina, M. Sekelja, A. Linløkken, R. Wilson, K. Rudi, Correlation between the human fecal microbiota and depression, Neurogastroenterol. Motil. 26 (2014), 1155-1162.

[38] C.E. Schretter, J. Vielmetter, I. Bartos, Z. Marka, S. Marka, S. Argade, S.K. Mazmanian, A gut microbial factor modulates locomotor behaviour in drosophila, Nature. 563 (2018), 402.

[39] E.A. Mayer, Gut feelings: the emerging biology of gut-brain communication, Nat. Rev. Neurosci. 12 (2011), 453.

[40] V. Tremaroli, F. Bäckh, Functional interactions between the gut microbiota and host metabolism, Nature. 489 (2012), 242.

[41] V.V. Roshchina, New trends and perspectives in the evolution of neurotransmitters in microbial, plant, and animal cells, in: M. Lyte (Eds.), Microbial Endocrinology: Interkingdom Signaling in Infectious Disease and Health, Springer, Cham, Switzerland, 2016, pp. 25-77.

[42] V.A. Shishov, T.A. Kirovskaya, V.S. Kudrin, A.V. Oleskin, Amine neuromediators, their precursors, and oxidation products in the culture of escherichia coli k-12, Appl. Biochem. Microbiol. 45 (2009), 494-497.

[43] F. Özoğul, E. Kuley, Y. ÖZOĞUL, İ. ÖZOĞUL, The function of lactic acid bacteria on biogenic amines production by foodborne pathogens in arginine decarboxylase broth, Food Sci. Technol. Res. 18 (2012), 795-804.

[44] W.A. Kunze, Y.-K. Mao, B. Wang, J.D. Huizinga, X. Ma, P. Forsythe, J. Bienenstock, Lactobacillus reuteri enhances excitability of colonic ah neurons by inhibiting calciumdependent potassium channel opening, J. Cell. Mol. Med. 13 (2009), 2261-2270.

[45] P. Blier, M.E. Mansari, Serotonin and beyond: therapeutics for major depression, Philos. Trans. R. Soc. B Biol. Sci. 368 (2013), $1-7$.

[46] M.E. Mansari, B.P. Guiard, O. Chernoloz, R. Ghanbari, N. Katz, P. Blier, Relevance of norepinephrine-dopamine interactions in the treatment of major depressive disorder, CNS Neurosci. Ther. 16 (2010), e1-e17.

[47] M.J. Nirenberg, C. Waters, Compulsive eating and weight gain related to dopamine agonist use, Mov. Disord. 21 (2006), 524-529.

[48] N.D. Volkow, G.-J. Wang, L. Maynard, M. Jayne, J.S. Fowler, W. Zhu, et al., Brain dopamine is associated with eating behaviors in humans, Int. J. Eating Disord. 33 (2003), 136-142.

[49] D.M. Tomkins, E.M. Sellers, Addiction and the brain: the role of neurotransmitters in the cause and treatment of drug dependence, CMAJ. 164 (2001), 817-821. https://www.cmaj.ca/ content/164/6/817.

[50] C. Chiapponi, F. Piras, F. Piras, C. Caltagirone, G. Spalletta, Gaba system in schizophrenia and mood disorders: amini review on third-generation imaging studies, Front. Psychiatry. 7 (2016), 61

[51] C.-Y. Lin, G.E. Tsai, H.-Y. Lane, Assessing and treating cognitive impairment in schizophrenia: current and future, Curr. Pharm. Design. 20 (2014), 5127-5138.

[52] H. Anisman, Z. Merali, M.O. Poulte, Gamma-aminobutyric acid involvement in depressive illness interactions with corticotropin-releasing hormone and serotonin, In: Y. Dwivedi (Ed.), The Neurobiological Basis of Suicide, CRC Press/Taylor \& Francis, Chicago, IL, USA, 2012. 
[53] B. Luscher, Q. Shen, N. Sahir, The gabaergic deficit hypothesis of major depressive disorder, Mol. Psychiatry. 16 (2011), 383.

[54] M.O. Poulter, L. Du, V. Zhurov, Altered organization of gabaa receptor mrna expression in the depressed suicide brain, Front. Mol. Neurosci. 3 (2010), 3.

[55] R.B. Lydiard, The role of gaba in anxiety disorders, J. Clin. Psychiatry. 64 (2003), 21-27. https://www.psychiatrist.com/jcp/ article/pages/2003/v64s03/v64s0304.aspx.

[56] F. Petty, G.L. Kramer, D. Dunnam, A.J. Rush, Plasma gaba in mood disorders, Psychopharmacol. Bull. 26 (1990), 157-161. https://psycnet-apa-org.vu-nl.idm.oclc.org/record/199235192-001.

[57] J.M. Wieronska, K. Stachowicz, G. Nowak, A. Pilc, The loss of glutamate-gaba harmony in anxiety disorders, in: Anxiety Disorders, V. Kalinin (Eds,), IntechOpen, Poland, 2011.

[58] A.A. Chadegani, H. Salehi, M.M. Yunus, H. Farhadi, M. Fooladi, M. Farhadi, N.A. Ebrahim, A comparison between two main academic literature collections: web of science and scopus databases, Asian Soc. Sci. 9 (2013), 18-26.

[59] A.W. Harzing, S. Alakangas, Google scholar, scopus and the web of science: a longitudinal and cross-disciplinary comparison, Scientometrics. 106 (2016), 787-804

[60] A. Martín-Martín, E. Orduna-Malea, M. Thelwall, E.D. López-Cózar, Google scholar, web of science, and scopus: a systematic comparison of citations in 252 subject categories, J. Informet. 12 (2018), 1160-1177.

[61] M.E Rose, J.R. Kitchin, Pybliometrics: Scriptable bibliometrics using a Python interface to Scopus, SoftwareX. 10 (2019), 100263.

[62] A.F. Thachil, R. Mohan, D. Bhugra, The evidence base of complementary and alternative therapies in depression, J. Affect. Disord. 97 (2007), 23-35.

[63] R.A. Gross, K.C. Johnston, Levels of evidence: taking neurology ${ }^{\circ}$ to the next level, Neurology. 72 (2009), 8-10.

[64] H.O. Stolberg, G. Norman, I. Trop, Randomized controlled trials, Am. J. Roentgenol. 183 (2004), 1539-1544.

[65] R.R.G. Knops, E.C. Van Dalen, R.L. Mulder, E. Leclercq, S.L. Knijnenburg, G.J.L. Kaspers, R. Pieters, H.N. Caron, L.C.M. Kremer, The volume effect in paediatric oncology: a systematic review, Ann. Oncol. 24 (2013), 1749-1753.

[66] R.P. Brown, J.J. Mann, A clinical perspective on the role of neurotransmitters in mental disorders, Psychiatr. Serv. 36 (1985), $141-150$.

[67] A.D. Mandić, A. Woting, T. Jaenicke, A. Sander, W. Sabrowski, U. Rolle-Kampcyk, M. von Bergen, M. Blaut, Clostridium ramosum regulates enterochromaffin cell development and serotonin release, Sci. Rep. 9 (2019), 1177.

[68] A. Mayr, G. Hinterberger, M.P. Dierich, C. Lass-Flörl, Interaction of serotonin with candida albicans selectively attenuates fungal virulence in vitro, Int. J. Antimicrob. Agents. 26 (2005), 335-337.

[69] M.G. Strakhovskaia, E.V. Ivanova, G. Frănkin, Stimulatory effect of serotonin on the growth of the yeast candida guilliermondii and the bacterium streptococcus faecalis, Mikrobiologiia. 62 (1993), 46-49. http://europepmc.org/abstract/MED/ 8505913.

[70] A.V. Oleskin, T.A. Kirovskaia, I.V. Botvinko, L.V. Lysak, Effect of serotonin (5-hydroxytryptamine) on the growth and differentiation of microorganisms, Mikrobiologiia. 67 (1998), 305-312. http://europepmc.org/abstract/MED/9702725.
[71] K.D. Malikina, V.A. Shishov, D.I. Chuvelev, V.S. Kudrin, A.V. Oleskin, Regulatory role of monoamine neurotransmitters in saccharomyces cerevisiae cells, Appl. Biochem. Microbiol. 46 (2010), 620-625.

[72] E.A. Tsavkelova, I.V. Botvinko, V.S. Kudrin, A.V. Oleskin, Detection of neurotransmitter amines in microorganisms with the use of high-performance liquid chromatography, in Doklady Biochemistry: Proceedings of the Academy of Sciences of the USSR, Biochemistry Section, Moscow, Russia, 2000, vol. 372, p. 115. http://europepmc.org/abstract/MED/10935181.

[73] M. Lyte, Probiotics function mechanistically as delivery vehicles for neuroactive compounds: microbial endocrinology in the design and use of probiotics, Bioessays. 33 (2011), 574-581.

[74] P.P.E. Freestone, R.D. Haigh, M. Lyte, Specificity of catecholamine-induced growth in escherichia coli o157: H7, salmonella enterica and yersinia enterocolitica, FEMS Microbiol. Lett. 269 (2007), 221-228.

[75] M. Hegde, T.K. Wood, A. Jayaraman, The neuroendocrine hormone norepinephrine increases pseudomonas aeruginosa pa14 virulence through the las quorum-sensing pathway, Appl. Microbiol. Biotechnol. 84 (2009), 763.

[76] P. Strandwitz, K.H. Kim, D. Terekhova, J.K. Liu, A. Sharma, J. Levering, et al., Gaba-modulating bacteria of the human gut microbiota, Nat. Microbiol. 4 (2019), 396.

[77] F. De Vadder, E. Grasset, L.M. Holm, G. Karsenty, A.J. Macpherson, L.E. Olofsson, F. Bäckh, Gut microbiota regulates maturation of the adult enteric nervous system via enteric serotonin networks, Proc. Nat. Acad. Sci. 115 (2018), 6458-6463.

[78] K. Pokusaeva, C. Johnson, B. Luk, G. Uribe, Y. Fu, N. Oezguen, et al., Gaba-producing bifidobacterium dentium modulates visceral sensitivity in the intestine, Neurogastroenterol. Motil. 29 (2017), e12904.

[79] E. Barrett, R.P. Ross, P.W. O’toole, G.F. Fitzgerald, C. Stanton, $\gamma$ aminobutyric acid production by culturable bacteria from the human intestine, J. Appl. Microbiol. 113 (2012), 411-417.

[80] C.-H. Wu, Y.-H. Hsueh, J.-M. Kuo, S.-J. Liu, Characterization of a potential probiotic lactobacillus brevis rk03 and efficient production of $\gamma$-aminobutyric acid in batch fermentation, Int. J. Mol. Sci. 19 (2018), 143.

[81] Y.R. Cho, J.Y. Chang, H.C. Chang, Production of gammaaminobutyric acid (gaba) by lactobacillus buchneri isolated from kimchi and its neuroprotective effect on neuronal cells, J. Microbiol. Biotechnol. 17 (2007), 104-109.

[82] N. Komatsuzaki, J. Shima, S. Kawamoto, H. Momose, T. Kimura, Production of $\gamma$-aminobutyric acid (gaba) by lactobacillus paracasei isolated from traditional fermented foods, Food Microbiol. 22 (2005), 497-504.

[83] S. Siragusa, M. De Angelis, R. Di Cagno, C.G. Rizzello, R. Coda, M. Gobbetti, Synthesis of $\gamma$-aminobutyric acid by lactic acid bacteria isolated from a variety of italian cheeses, Appl. Environ. Microbiol. 73 (2007), 7283-7290.

[84] Y.-C. Su, J.-J. Wang, T.-T. Lin, T.-M. Pan, Production of the secondary metabolites $\gamma$-aminobutyric acid and monacolin $\mathrm{k}$ by monascus, J. Indus. Microbiol. Biotechnol. 30 (2003), 41-46.

[85] S.-Y. Yang, F.-X. Lü, Z.-X. Lu, X.-M. Bie, Y. Jiao, L.-J. Sun, B. Yu, Production of $\gamma$-aminobutyric acid by streptococcus salivarius subsp. Thermophilus y2 under submerged fermentation, Amino Acids. 34 (2008), 473-478. 
[86] S.-H. Kim, B. Ben-Gigirey, J. Barros-Velazquez, R.J. Price, H. An, Histamine and biogenic amine production by morganella morganii isolated from temperature-abused albacore, J. Food Prot. 63 (2000), 244-251.

[87] J. Scheffer, W. König, J. Hacker, W. Goebel, Bacterial adherence and hemolysin production from escherichia coli induces histamine and leukotriene release from various cells, Infect. Immun. 50 (1985), 271-278.

[88] M. Diaz, B. del Rio, V. Ladero, B. Redruello, M. Fernández, M.C. Martin, M.A. Alvarez, Isolation and typification of histamine-producing lactobacillus vaginalis strains from cheese, Int. J. Food Microbiol. 215 (2015), 117-123.

[89] R. Ursin, Serotonin and sleep, Sleep Med. Rev. 6 (2002), 55-67.

[90] H. Steiger, Eating disorders and the serotonin connection: state, trait and developmental effects, J. Psychiatry Neurosci. 29 (2004), 20-29.

[91] E.M. Hull, J.W. Muschamp, S. Sato, Dopamine and serotonin: influences on male sexual behavior, Physiol. Behav. 83 (2004), 291-307.

[92] T. Jenkins, J. Nguyen, K. Polglaze, P. Bertrand, Influence of tryptophan and serotonin on mood and cognition with a possible role of the gut-brain axis, Nutrients. 8 (2016), 56.

[93] P.J. Cowen, M. Browning, What has serotonin to do with depression?, World Psychiatry. 14 (2015), 158-160.

[94] K.M. Nautiyal, R. Hen, Serotonin receptors in depression: from Ato B, F1000Research. 6 (2017), 123.

[95] A. Neumeister, Tryptophan depletion, serotonin, and depression: where do we stand?, Psychopharmacol. Bull. 37 (2003), 99-115. http://europepmc.org/abstract/MED/15131521.

[96] A.J.W. Van der Does, The effects of tryptophan depletion on mood and psychiatric symptoms, J. Affect. Disord. 64 (2001), 107-119.

[97] B.W. Dunlop, C.B. Nemeroff, The role of dopamine in the pathophysiology of depression, Arch. Gen. Psychiatry. 64 (2007), 327-337.

[98] A.A. Grace, P. Belujon, Dopamine system dysregulation in major depressive disorders, Int. J. Neuropsychopharmacol. 20 (2017), 1036-1046.

[99] L.F. Burbulla, P. Song, J.R. Mazzulli, E. Zampese, Y.C. Wong, S. Jeon, et al., Dopamine oxidation mediates mitochondrial and lysosomal dysfunction in parkinson's disease, Science. 357 (2017), 1255-1261.

[100] K.J. Ressler, C.B. Nemeroff, Role of norepinephrine in the pathophysiology and treatment of mood disorders, Soc. Biol. Psychiatry. 46 (1999), 1219-1233.

[101] J.J. Schildkraut, The catecholamine hypothesis of affective disorders: areview of supporting evidence, Am. J. Psychiatry. 122 (1965), 509-522.

[102] C.Y. Ko, H.-T.V. Lin, G.J. Tsai, Gamma-aminobutyric acid production in black soybean milk by lactobacillus brevis fpa 3709 and the antidepressant effect of the fermented product on a forced swimming rat model, Process Biochem. 48 (2013), 559-568.

[103] M. Nishimura, S.-I. Yoshida, M. Haramoto, H. Mizuno, T. Fukuda, H. Kagami-Katsuyama, A. Tanaka,T. Ohkawara, Y. Sato, J. Nishihira, Effects of white rice containing enriched gamma-aminobutyric acid on blood pressure, J. Tradit. Complement. Med. 6 (2016), 66-71.
[104] J. Taneera, Z. Jin, Y. Jin, S.J. Muhammed, E. Zhang, S. Lang, et al., $\gamma$-aminobutyric acid (gaba) signalling in human pancreatic islets is altered in type 2 diabetes, Diabetologia. 55 (2012), 1985-1994.

[105] F. Petty, Gaba and mood disorders: a brief review and hypothesis, J. Affect. Disord. 34 (1995), 275-281.

[106] C.G.W. Wong, T. Bottiglieri, O.C. Snead III, Gaba, $\gamma$ hydroxybutyric acid, and neurological disease, Ann. Neurol. 54 (2003), S3-S12.

[107] W. Barcik, M. Wawrzyniak, C.A. Akdis, L. O’Mahony, Immune regulation by histamine and histamine-secreting bacteria, Curr. Opin. Immunol. 48 (2017), 108-113.

[108] S. Norn, P. Stahl Skov, C. Jensen, J.O. Jarløv, F. Espersen, Histamine release induced by bacteria. A new mechanism in asthma?, Agents Actions. 20 (1987), 29-34.

[109] M. Steriade, Acetylcholine systems and rhythmic activities during the waking-sleep cycle, Prog. Brain Res. 145 (2004), 179-196.

[110] M.J. Higley, M.R. Picciotto, Neuromodulation by acetylcholine: examples from schizophrenia and depression, Curr. Opin. Neurobiol. 29 (2014), 88-95.

[111] M.T. Bailey, S.E. Dowd, J.D. Galley, A.R. Hufnagle, R.G. Allen, M. Lyte, Exposure to a social stressor alters the structure of the intestinal microbiota: implications for stressorinduced immunomodulation, Brain Behav. Immun. 25 (2011), 397-407.

[112] C. Sherman, NIDA Notes Contributing Writer, The defining features of drug intoxication and addiction can be traced to disruptions in cell-to-cell signaling, NIDA Notes Natl. Inst. Health Natl. Inst. Drug Abuse. 21 (2007). https://www.addictioncounselorce. com/articles/101591/101591.pdf.

[113] J. Bienenstock, W. Kunze, P. Forsythe, Microbiota and the gutbrain axis, Nutr. Rev. 73 (2015), 28-31.

[114] J.F. Cryan, S.M. O'mahony, The microbiome-gut-brain axis: from bowel to behavior, Neurogastroenterol. Motil. 23 (2011), 187-192.

[115] K.M. Neufeld, N. Kang, J. Bienenstock, J.A. Foster, Reduced anxiety-like behavior and central neurochemical change in germ-free mice, Neurogastroenterol. Motil. 23 (2011), 255-e119.

[116] J.-X. Pan, F.-L. Deng, B.-H. Zeng, P. Zheng, W.-W. Liang, B.-M. Yin, et al., Absence of gut microbiota during early life affects anxiolytic behaviors and monoamine neurotransmitters system in the hippocampal of mice, J. Neurol. Sci. 400 (2019), 160-168.

[117] L. Jianguo, J. Xueyang, W. Cui, W. Changxin, Q. Xuemei, Altered gut metabolome contributes to depression-like behaviors in rats exposed to chronic unpredictable mild stress, Trans. Psychiatry. 9 (2019), 40

[118] K.D. McGaughey, T. Yilmaz-Swenson, N.M. Elsayed, D.A. Cruz, R.M. Rodriguiz, M.D. Kritzer, et al., Relative abundance of akkermansia spp. and other bacterial phylotypes correlates with anxiety-and depressive-like behavior following social defeat in mice, Sci. Rep. 9 (2019), 3281.

[119] I. Lukić, D. Getselter, O. Ziv, O. Oron, E. Reuveni, O. Koren, E. Elliott, Antidepressants affect gut microbiota and ruminococcus flavefaciens is able to abolish their effects on depressive-like behavior, Trans. Psychiatry. 9 (2019), 133. 
[120] X. Yuan, Y. Kang, C. Zhuo, X.-F. Huang, X. Song, The gut microbiota promotes the pathogenesis of schizophrenia via multiple pathways, Biochem. Biophys. Res. Commun. 512 (2019), 373-380.

[121] K. Korpela, A. Salonen, L.J. Virta, R.A. Kekkonen, K. Forslund, P. Bork, W.M. De Vos, Intestinal microbiome is related to lifetime antibiotic use in finnish pre-school children, Nat. Commun. 7 (2016), 10410.

[122] S.E. Aidy, T.G. Dinan, J.F. Cryan, Immune modulation of the brain-gut-microbe axis, Front. Microbiol. 5 (2014), 146.

[123] M. Carabotti, A. Scirocco, M.A. Maselli, C. Severi, The gut-brain axis: interactions between enteric microbiota, central and enteric nervous systems, Ann. Gastroenterol. Quart. Publ. Hellenic Soc. Gastroenterol. 28 (2015), 203. https://www.ncbi.nlm.nih.gov/ pmc/articles/PMC4367209/pdf/AnnGastroenterol-28-203.pdf.

[124] E.A. Mayer, K. Tillisch, A. Gupta, Gut/brain axis and the microbiota, J. Clin. Invest. 125 (2015), 926-938.

[125] H.-X. Wang, Y.-P. Wang, Gut microbiota-brain axis, Chin. Med. J. 129 (2016), 2373.

[126] L. Zhuang, H. Chen, S. Zhang, J. Zhuang, Q. Li, Z. Feng, Intestinal microbiota in early life and its implications on childhood health, Genom. Proteom. Bioinf. 17 (2019), 13-25. 